\title{
Morphometric, isozymic and mitochondrial variability of Africanized honeybees in Costa Rica
}

\author{
JORGE A. LOBO \\ Escuela de Biologia, Universidad de Costa Rica, San José, Costa Rica
}

\begin{abstract}
Wing morphometry, isozymic variation and mitochondrial RFLPs were studied in samples of feral Africanized bees collected at three different locations in Costa Rica, two of them in the lowlands (Guanacaste and Golfito regions) and the other in the Central Valley. These data revealed a predominantly African origin at all locations. However, significant heterogeneity was found between the two lowland sites and the Central Valley for some isozyme markers as well as for the RFLPs considered in this study. Both isozymic and mitochondrial DNA European markers were more frequent in the Central Valley. This could be the result of different opportunities for European gene introgression at the beginning of the migration of Africanized honeybees. It is shown that different gene frequencies of mitochondrial and nuclear European genetic markers may exist in Africanized bee populations, and that this may result from different selection pressures among colonies with African and European queens.
\end{abstract}

Keywords: Africanized honeybees, isozymes, migration, mitochondrial DNA, morphometrics, social insects.

\section{Introduction}

The Neotropical spread of the Africanized honeybee (derived from Apis mellifera scutellata, one of the African subspecies of Apis mellifera), has given biologists the opportunity to study the genetic and ecological characteristics of a good colonist. The migration of these bees through the continent has produced a new kind of feral honeybee population in a variety of habitats, which had sustained low densities of feral honeybees prior to 'Africanization'. Comparative studies of behaviour, population dynamics and morphometrics have revealed that these new bee populations are very similar to their African ancestors (summarized by Michener, 1975; Winston, 1992). Genetic polymorphism data have supported this conclusion, except in some regions where higher frequencies of European alleles can be detected (Lobo et al., 1989; Rinderer et al., 1991; Sheppard et al., 1991b). The latter phenomenon may be a result of prior high population densities or continued introduction of other honeybee races and/or ecological constraints for Africanized bees.

These facts have led some authors to conclude that selective forces and the abundance of potential niches for tropical honeybees in the Neotropics have produced an essentially African population, free of new genetic variability because of a lack of hybridization with other honeybee races (Smith et al., 1989; Wallace, 1992).

The arrival of Africanized honeybees in regions with other honeybee races is a case where the joint action of gene flow and selection on some gene complexes determines the frequencies of racial markers. Opportunities for the introgression of European alleles are very different at different loci: polymorphism at loci that influence selectively important traits should disappear in a few generations, but alleles at other polymorphic loci can, through recombination, subsist in an 'African' genetic background. For example, some isozymic data show low but significant percentages of alleles of European origin (Lobo et al., 1989; Sheppard et al., 1991a). However, mitochondrial DNA RFLPs (mitotypes) are of African origin in most of the samples (Sheppard et al., 1991a). It seems that the allele frequency pattern in Neotropical honeybees can provide information about the consequences of hybridization of Africanized bees. However, the interpretation of gene frequencies at racial marker loci must take into account the dynamics of gametic disequilibrium with admixture and selection, which can result in evolution toward different equilibrium frequencies at different marker loci. 
In Costa Rica the first Africanized swarms arrived in 1982-1983, and an abundant local Africanized population had already settled in most Costa Rican regions by 1984 (Ramirez, 1992; Spivak, 1991). Costa Rica has particular geographical and ecological characteristics that make it an interesting site for genetic research on Africanized honeybees. Firstly, the rainy lowlands have been successfully colonized by Africanized honeybees, especially in disturbed (unforested) habitats (J. A. Lobo, personal observation). Honeybees were nearly nonexistent in these regions before. Data from these populations may reveal the genetic status, in terms of genetic polymorphisms, of Africanized honeybees after migration through South America. On the other hand, the Central Valley of Costa Rica is a midelevation (700-1600 $\mathrm{m}$ ) region with a cooler and drier climate, and prior existence of beekeeping and wild European-derived honeybees may have favoured introgression of European alleles.

Spivak (1992) showed that swarming and survival advantages of Africanized honeybees over European ones decrease with altitude in Costa Rica. Although quantification of the magnitude of survival and swarming rates in honeybee populations is a very difficult task, it seems that the main difference in the population dynamics between these two races is the higher swarming rate of African honeybees in Costa Rican lowlands $(800 \mathrm{~m})$. However, neither race performed better in the highlands $(2800 \mathrm{~m})$, where lower survival probabilities and swarming rates are typical.

In this study morphometric, isozymic and mitochondrial data were obtained from samples of wild honeybees from localities in the lowlands and the Central Valley of Costa Rica. The data reveal that significant divergence exists between these two regions in the frequencies of some genetic markers. This could be a result of differing opportunities for European gene introgression. This pattern seems to be similar to that observed in South American surveys, and suggests that ecological heterogeneity along the Africanized bee distribution may have resulted in a 'mosaic' of allele frequencies at racial marker loci.

\section{Methods}

\section{Sampling}

Sampling of swarms was carried out during the rainy season (July-November) of 1992 and the dry season (December-May) of 1993 in three localities in the Central Valley of Costa Rica (Santo Domingo de Heredia, the campus of the University of Costa Rica and Ciudad Colón) and from two localities in the Pacific lowlands (Palo Verde in Guanacaste province and Golfito in Puntarenas province). The Central Valley is a mid-elevation region $(800-1600 \mathrm{~m})$ of basically tropical premontane moist forests (Holdridge, 1967). Palo Verde is in the Tropical Dry Forest zone (mean elevation $100 \mathrm{~m}$ ). Substantial beekeeping was present in Palo Verde and in the Central Valley both before and after the arrival of the Africanized honeybees. Golfito is located in the Tropical Rain Forest zone in southeastern Costa Rica, with little beekeeping before Africanization.

Special care was taken to sample only wild swarms or colonies. The introduction of European queens, as is occasionally carried out by some beekeepers in Costa Rica (W. Ramirez, personal communication), is a factor that can introduce a bias when samples from apiaries are taken. But swarms or natural colonies are more representative of the genetic makeup of wild populations because of the extensive dispersion of honeybee swarms. It is difficult to eliminate, however, the possibility that some 'wild' swarms were really 'feral' groups or descendants that had escaped from apiaries.

Swarms were trapped in cardboard boxes placed in trees. Thirty boxes were placed in each locality before the swarming season, and they were visited monthly. Most of the colony samples, especially from natural colonies, consisted of only workers. Queens and sometimes drones were obtained from swarms caught in the boxes. Samples were frozen and transported to the laboratory, where morphometric, isozymic and mitochondrial RFLP analyses were performed. Table 1 shows the distribution of the number of colonies sampled per locality and the type of analysis performed.

\section{Morphometry}

Wing measurements were used as the source of morphometric data, following the methodology suggested by Du Praw (1965) and applied to Africanized honeybees by Lobo et al. (1989) and Moritz \& Meusel (1992). These traits were shown to be adequate for discriminating between honeybee races because of their high variation and heritability (Du Praw, 1965; Poklukar et al., 1994). Thirteen angles between wing veins, plus length and width of the wing, were measured in eight workers per colony, using right forewings mounted on microscope slides with Permount resin. Images of the wings were projected onto paper using a projection microscope, where angles (to the nearest 0.5 degree) and sizes of the wings were measured.

To compare Costa Rican Africanized populations with hypothetical ancestral populations, three groups 
Table 1 Number of colonies of honeybees sampled for each locality and method of racial discrimination applied in this study

\begin{tabular}{lccccc}
\hline Localities & $M D H$ & $\begin{array}{c}\text { Isozymes } \\
H K\end{array}$ & $A D H$ & $\begin{array}{c}\text { Wing } \\
\text { morphometry }\end{array}$ & $\begin{array}{c}\text { DNAmit } \\
\text { mitotypes }\end{array}$ \\
\hline Central Valley & 20 & 15 & 5 & 10 & 20 \\
Golfito & 14 & 11 & 2 & 7 & 15 \\
Palo Verde & 8 & 8 & 4 & 7 & 7 \\
\hline
\end{tabular}

of data were used as a reference: Africanized honeybees from Brazil, European honeybees from Costa Rica prior to Africanization and European honeybees from eastern Uruguay. The Brazilian honeybees serve as a sample of the morphometric variability of Africanized honeybees. European honeybees from Costa Rica and Uruguay were used because they represent a sample of morphometric variability of Neotropical honeybees of European origin. Costa Rican samples were taken from specimens preserved prior to 1978 in the University of Costa Rica Entomological Museum, with individuals chosen from different localities and dates of collection. Uruguayan samples were taken and analysed by Lobo et al. (1989) and represent a sample of native Apis mellifera mellifera stocks, introduced in the nineteenth century. Brazilian samples were collected in a survey of different apiaries from northeastern and southeastern Brazil (Lobo et al., 1989).

Analyses of morphometric data were performed by univariate and multivariate approaches. The means of each variable were compared between populations by Duncan's multiple range test. Multivariate analysis was performed by discriminant analysis. Firstly, two discriminant functions were obtained for crude measurements of the reference populations. Then coefficients of the former functions were used to calculate discriminant scores for each individual of Costa Rican Africanized populations and these were plotted on a graph for comparison.

\section{Isozymes and mitochondrial DNA analysis}

A mean of 10 adult workers per colony were typed for $M D H, P G M, H K, E S T-3$ and $A D H$ genotypes in starch gel electrophoresis, using the methods of Lobo et al. (1989) and Del Lama et al. (1988). These enzymes represent most of the polymorphic enzyme loci known in honeybees, and some of them ( $M D H$ and $H K)$ have race-specific alleles. When available, the queen's genotype and/or drones' genotypes were also scored. Allele frequencies at each locus were estimated by the maximum likelihood method for honeybee population structure suggested by Lobo \& Krieger (1992). Hetero- geneity between regions (Central Valley, Palo Verde and Golfito) was tested by likelihood ratio tests (Elandt-Johnson, 1971), by summing the regional values of $\mathbf{U}^{\prime} \mathbf{K U}$ for a joint estimation of gene frequencies, where $\mathbf{U}$ is the scores vector and $\mathbf{K}$ the information matrix of each of the regions (Lobo et al., 1989).

Mitotypes were scored from one worker per sampled colony. Distinction between the European or African origins of mitochondrial DNA was made by PCR amplification of polymorphic regions of mitochondrial DNA, following the methods of Hall \& Smith (1991). For this, total DNA of one individual worker was isolated by the procedure of Hall 1990. PCR amplification was performed using two of the primer pairs recommended by Hall \& Smith (1991). The first one amplifies a region of the Large Ribosomal Unit $(L R S)$ gene, which contains an EcoRI restriction site specific for southeast European honeybees (Apis mellifera ligustica and Apis mellifera carnica). The second one amplifies a region of the Cytochrome Oxidase I gene $(C I)$, which has an HincIl restriction site in northwest European honeybees (Apis mellifera mellifera). PCR amplifications were performed using the mixture reaction and conditions recommended by the above authors. After amplification, samples were digested with EcoRI or HincII and the bands were visualized in a 2 per cent agarose gel stained with ethidium bromide. Each sample was classified as mitotype,--+- or -+ , which indicates presence $(+)$ or absence (-) of restriction sites for EcoRI and HincII, respectively. Mitotype ++ is not expected to appear because no race has the two sites simultaneously in the two mitochondrial loci.

\section{Results}

\section{Morphometry}

Wing length and width of Costa Rican Africanized bees were on average smaller than comparable measurements on European bees, very similar to the typical Africanized-African pattern (Table 2). In the whole Costa Rican sample, the variances of all the 
Table 2 Sample means and standard deviations (in parentheses) of wing measurements for populations of honeybees

\begin{tabular}{lcrrr}
\hline Variable & $\begin{array}{c}\text { Costa Rican } \\
\text { Europeans }\end{array}$ & $\begin{array}{c}\text { Brazilian } \\
\text { Africanized }\end{array}$ & $\begin{array}{c}\text { Uruguayan } \\
\text { Europeans }\end{array}$ & $\begin{array}{r}\text { Costa Rican } \\
\text { Africanized }\end{array}$ \\
\hline A4 & $30.8(2.0)$ & $32.7(2.4)$ & $\underline{31.8(1.1)}$ & $31.8(2.2)$ \\
E9 & $22.0(1.7)$ & $\underline{19.2(1.4)}$ & $18.3(1.9)$ & $19.4(1.3)$ \\
G7 & $24.9(0.9)$ & $23.5(1.1)$ & $22.9(1.0)$ & $23.9(1.1)$ \\
G18 & $\underline{97.7(4.4)}$ & $100.5(3.0)$ & $101.4(3.8)$ & $98.1(3.5)$ \\
H12 & $22.0(1.9)$ & $\underline{19.9(1.9)}$ & $\underline{21.2(1.8)}$ & $20.2(2.1)$ \\
M17 & $\underline{57.7(4.8)}$ & $54.8(6.0)$ & $\underline{59.2(3.4)}$ & $56.9(5.1)$ \\
N23 & $\underline{92.0(3.2)}$ & $90.0(3.5)$ & $90.5(2.9)$ & $92.2(3.2)$ \\
Q21 & $37.8(2.5)$ & $36.8(1.8)$ & $\underline{35.8(1.2)}$ & $35.9(1.5)$ \\
A_O & $212.2(4.4)$ & $200.8(4.3)$ & $210.6(3.6)$ & $203.4(4.9)$ \\
L_G & $97.7(2.3)$ & $\underline{91.6(2.6)}$ & $95.0(1.4)$ & $92.1(2.4)$ \\
$N$ & 47 & 96 & 20 & 210 \\
\hline
\end{tabular}

Names of the variables (Du Praw, 1965) refer to wing angles (A4-Q21) measured in degrees, wing length $\left(A_{-} O\right)$ and wing width $\left(L_{-} G\right)$ in millimeters at a magnification of $48 \times$. Underlined numbers represent sample means not significantly different from Costa Rican Africanized bees.

$N=$ sample size for number of workers.

measurements were very similar to the ones of the reference populations, as can be seen in Table 2. This suggests that the data were not influenced by a particular locality or group of colonies with very marked European morphometry, which might have increased the variances because of the sampling of a racially heterogeneous population.

The two discriminant functions produced by discriminant analysis are shown in Fig. 1. Each reference population is enclosed by an ellipse that encircles 95 per cent of the points in the plane defined by the two discriminant functions. As can be observed, the Costa Rican European bees and the Brazilian Africanized bees are well separated by discriminant function 1 . Function 2 separates, but not so well, the Uruguayan European from the other populations. Centroids of bee populations from Europe and Africa are also plotted in this figure. These values were estimated using raw data published by Du Praw (1965). Costa Rican European bees seem to be derived from southeast European races, perhaps because of the preferential use of these races in beekeeping. Most of the Costa Rican Africanized bees are within the ellipse of Brazilian Africanized bees, but many points ( 30 out of 192 bees) are within the distribution of European bees. One-way analysis of variance of the scores of discriminant function 1 for Costa Rican Africanized bees does not show statistical significance of the between-region (Central Valley, Golfito and Palo Verde) component of variance.

\section{Isozymes}

The $M D H, H K$ and $A D H$ loci were polymorphic in Africanized bee populations of Costa Rica. The $P G M$ and EST-3 loci did not reveal any of the rare alleles that can be detected in almost every Brazilian population of honeybees (Del Lama et al., 1988; Lobo et al., 1989; Sheppard et al., 1991a). Very remarkable is the abscence of the $P G M^{S}$ allele, very possibly of African origin, which has not been detected in Costa Rica in the present or past surveys (Spivak et al., 1988; Del Lama et al., 1990).

The $A D H$ locus is expressed only in pupae or larvae, which could be sampled only in a limited number of colonies. Therefore only a global estimation of allele frequencies for Costa Rica was made $\left(A D H^{l}=0.287 \pm 0.05, A D H^{2}=0.674 \pm 0.05, A D H^{3}=\right.$ 0.038 ). These frequencies are very similar to those of Brazilian populations. This locus is highly heterozygous in several honeybee populations, with small differences in the allele frequencies between races (Martins et al., 1977).

Table 3 shows the estimates of allele frequencies for $M D H$ and $H K$, with their respective standard errors. As is the regular pattern in Africanized honeybees, the most frequent allele at the $M D H$ locus is $M D H^{A}$, followed by $M D H^{B}$ and $M D H^{C}$, which are of European origin. It can be inferred from worker data that there was no colony or swarm with a homozygous queen for these European alleles. Heterozygous

(c) The Genetical Society of Great Britain, Heredity, 75, 133-141. 


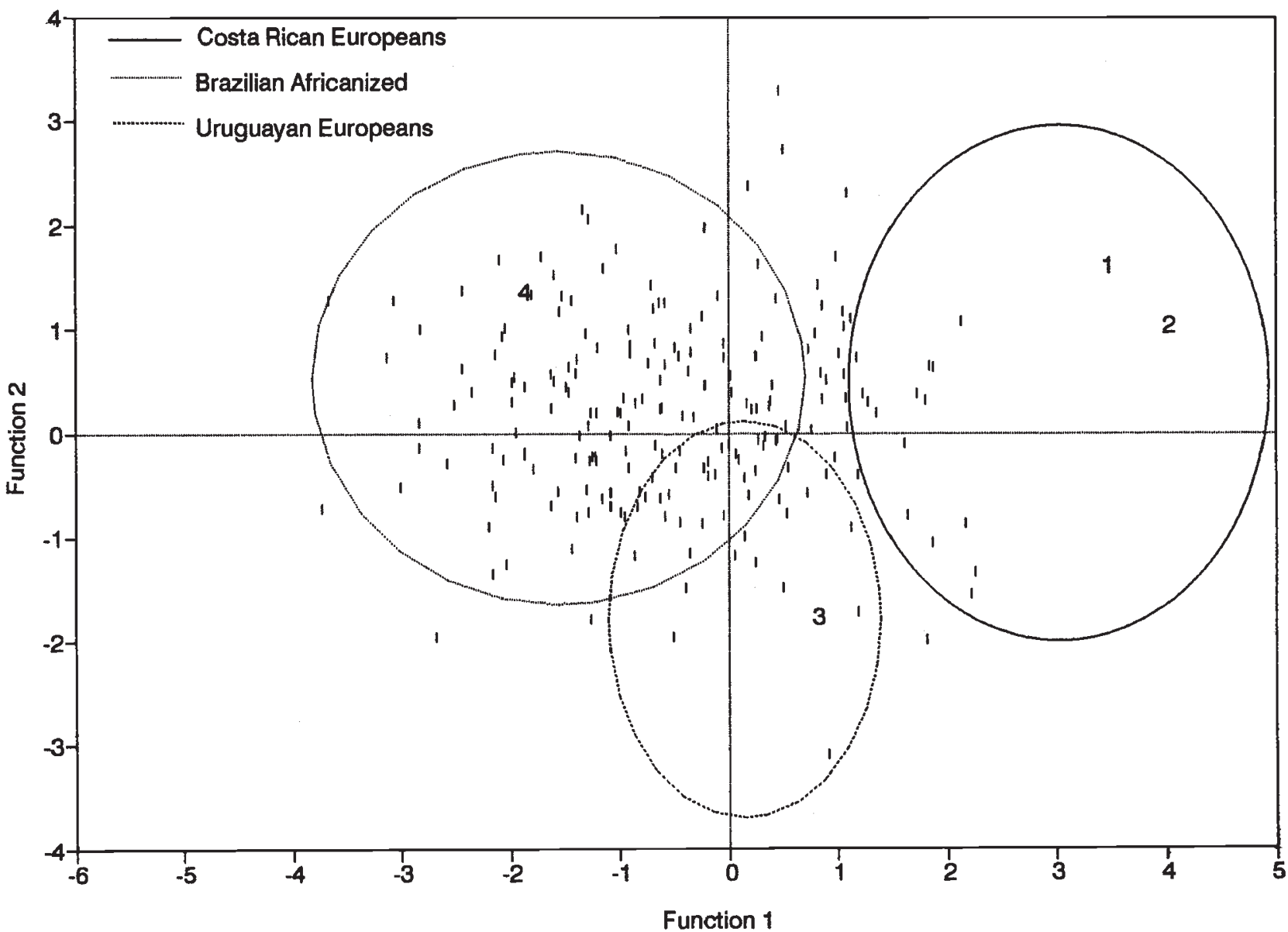

Fig. 1 Plot of discriminant functions 1 and 2 of Africanized honeybees from three localities of Costa Rica (oblong points). The ellipses drawn in the figure encircle 95 per cent of the distribution of three 'reference' bee populations. 1 and 2 are the centroids of Apis mellifera carnica and A. m. ligustica, respectively, 3 is the same for A. m. mellifera and 4 for A.m. scutellata, from South Africa (from Du Praw, 1965).

Table 3 Allele frequencies for the $M D H$ and $H K$ loci of Costa Rican honeybees (standard errors in parentheses)

\begin{tabular}{|c|c|c|c|c|c|}
\hline \multirow[b]{2}{*}{ Localities } & \multicolumn{3}{|c|}{$M D H$} & \multicolumn{2}{|c|}{$H K$} \\
\hline & $A$ & $B$ & $C$ & $F$ & $S$ \\
\hline Central Valley & $\begin{array}{c}0.743 \\
(0.040)\end{array}$ & $\begin{array}{c}0.179 \\
(0.034)\end{array}$ & 0.077 & $\begin{array}{c}0.455 \\
(0.072)\end{array}$ & 0.545 \\
\hline Palo Verde & $\begin{array}{c}0.842 \\
(0.050)\end{array}$ & $\begin{array}{c}0.128 \\
(0.040)\end{array}$ & 0.028 & $\begin{array}{c}0.513 \\
(0.030)\end{array}$ & 0.487 \\
\hline Golfito & $\begin{array}{c}0.937 \\
(0.020)\end{array}$ & $\begin{array}{c}0.056 \\
(0.020)\end{array}$ & 0.007 & $\begin{array}{c}0.505 \\
(0.033)\end{array}$ & 0.443 \\
\hline Costa Rica & $\begin{array}{c}0.827 \\
(0.023)\end{array}$ & $\begin{array}{c}0.128 \\
(0.020)\end{array}$ & 0.045 & $\begin{array}{c}0.505 \\
(0.033)\end{array}$ & 0.495 \\
\hline$\chi^{2}$ & \multicolumn{3}{|c|}{$24.19_{6 \text { d.f. }} P<0.01$} & \multicolumn{2}{|c|}{$4.88_{4 \text { d.f. }} P>0.10$} \\
\hline
\end{tabular}

$\chi^{2}$ is a test of heterogeneity of allele frequencies between localities. queens $M D H^{A} / M D H^{B}$ or $M D H^{A} / M D H^{C}$ can be detected in the Central Valley, as well as some $M D H^{B}$ and $M D H^{C}$ drones mated with these queens. In Golfito and Palo Verde, segregation of these alleles in some colonies was evidently a result of mating with some rare drones carrying European alleles. This pattern is a consequence of the highly polyandrous mating system of honeybee queens, which ensures better sampling of male gametes relative to female ones when workers are the source of information about population allele frequencies.

There was no evidence of differences in allele frequencies between the sexes for the $M D H$ and $H K$ loci. The likelihood ratio test suggested by Lobo \& Krieger (1992) did not reject the null hypothesis $\left(\chi_{2}^{2}=0.89\right)$ that both sexes had similar allele frequencies. 
In relation to regional heterogeneity of allele frequencies, the likelihood ratio test shows significance of the regional component at the $M D H$ locus but not at the $H K$ locus (Table 3). The frequency of the $M D H^{A}$ allele is near 0.95 in Golfito, decreases to 0.85 in Palo Verde and to 0.75 in the Central Valley. Increases in both $M D H^{B}$ and $M D H^{C}$ frequencies occur in the Central Valley. The frequency of the $H K$ alleles oscillates in the range of 0.5 , which is very close to the mean frequency of Brazilian populations. This polymorphism arrived in Costa Rica with Africanized bees, as demonstrated by Spivak et al. (1989).

\section{Mitochondrial DNA}

Haplotype '- -' was the most frequent in the Central Valley and Palo Verde, and it was the only one found in the Golfito region (Table 4). Haplotype ' +- ', of southeast European origin, was found in the Central Valley in four swarms caught in cardboard boxes, three in Santo Domingo de Heredia and one in Ciudad Colón. A fifth European haplotype was found in Palo Verde, from a colony in a natural cavity. Haplotype '- +' (of Apis mellifera mellifera origin) was not seen in the samples.

The banding pattern of the PCR amplification of the $L R S$ gene and restriction enzyme digestion with EcoRI was similar to the ones reported by Hall \& Smith (1991). The size of the amplified region was approximately $738 \mathrm{bp}$ and samples containing an EcoRI restriction site produced two fragments of 483 bp and 251 bp, respectively.

\section{Discussion}

The diversity of allele frequencies at the $M D H$ locus between the three Costa Rican regions is higher than the genetic variation that has been detected between Brazilian populations separated by distances of thousands of kilometers (Lobo et al., 1989). However,

Table 4 Frequencies of three mitochondrial DNA haplotypes of Costa Rican Africanized honeybee populations

\begin{tabular}{lcccc}
\hline \multicolumn{2}{c}{ Mitotype } & \multicolumn{4}{c}{ Locality } \\
\cline { 3 - 5 } EcoRI- & HincII- & \multicolumn{3}{c}{} \\
\cline { 3 - 5 }$L R S$ site & CI site & Central Valley & Palo Verde & Golfito \\
\hline- & - & 16 & 6 & 15 \\
+ & - & 4 & 1 & 0 \\
- & + & 0 & 0 & 0 \\
\hline
\end{tabular}

it can be suggested that the origin of both processes is the same: (i) regional differences in the initial rate of population growth of Africanized migrants; and (ii) regional differences in the abundance of Europeanderived bee populations before 'Africanization'. In Costa Rica, the genetic differences between populations have been allowed to accumulate by topographical (mountains) and climatic differences between lowlands and intermountain valleys. The occasional occurrence of colonies with European mitotypes in the Central Valley and Palo Verde correlates well with the pattern observed at the $M D H$ locus.

Allele frequencies for the $H K$ and $M D H$ loci show different geographical patterns; allele frequencies for $H K$ do not vary much between regions, whereas allele frequencies for $M D H$ show significant geographical variation. This same pattern occurs in Brazil (Del Lama et al., 1990). Paucity of isozyme polymorphisms in Apis mellifera has prevented the comparison of geographical patterns of $M D H$ alleles with other loci. If it were proven that several loci behaved in a way similar to $M D H$, then this would support the notion of racial admixture as the main cause of geographical heterogeneity. Whereas if $M D H$ were the sole gene behaving in such a way we would then attribute it to locus-specific effects, for example selection of $M D H$ alleles under different climatic regimes. However, a statistical analysis of racial admixture in Brazil did not detect significant heterogeneity between loci in racial admixture proportions (Lobo \& Krieger, 1992). It must be noted that $H K$ is not as good a racial marker in Apis mellifera as $M D H$. Allele frequencies near 0.5 for $H K$ alleles in African races leads to high variances of frequencies because of population and sampling effects, preventing the detection of small differences in racial admixture proportions as are supposed to exist between samples of Africanized bees.

A sample of Africanized bees taken from the Central Valley of Costa Rica in 1987 (Del Lama et al., 1988) gave estimates of the $M D H^{A}$ frequency very similar to the present sample from the same region. Del Lama et al. (1988) questioned whether the greater proportion of European alleles in Costa Rica compared with Brazil results from hybridization of Africanized bees during migration (through Brazil and northern Southern America), or from 'in situ' hybridization of recent migrants with local established populations. Given the strong differences in $M D H$ allele frequencies between the Central Valley and Golfito, with Palo Verde in an intermediate status, the more plausible explanation is 'in situ' hybridization of a migrant population with African genetic characteristics.

Morphometric analyses and mitotype frequencies do not conflict with isozyme data, in terms of the detec- 
tion of low levels of European admixture in some localities of this survey (Palo Verde and Golfito). In other population studies (Sheppard et al., 1991a), European DNAmit mitotypes have not been detected, whereas isozymic alleles of European origin have been found in low frequencies in the same populations. Sheppard et al. (1991a) and Lobo \& Krieger (1992) have suggested the following two hypotheses to explain the apparent contradiction between the data on isozymes and those on mitochondrial DNA.

Sampling error Effective sample sizes of nuclear loci tend to be higher than those for mitochondrial variants. For example, in Golfito a joint frequency of $M D H$ European alleles of 0.06 was estimated. The probability of not detecting of a DNAmit variant with the same frequency is $(0.94)^{15}=0.39$, with a sample size of 15 colonies as in Golfito.

Maternal effects Even when a higher number of colonies has been sampled, the population frequencies of both markers may be different. The survival and fertility of colonies with an African queen mated to European and Africanized drones can be higher than colonies resulting from crosses with a European queen mated to the same pool of drones, because of the presence of an African queen genotype and higher frequencies of African alleles in the workers. This favours greater introgression of European nuclear alleles compared with mitochondrial ones.

Using a simulation based on a colony-selection model (see Appendix), the conditions that create different population frequencies of European nuclear and DNAmit markers were analysed in more detail. A simplified 'hitchhiking' scheme is assumed, where an adaptative African gene, unlinked with genetic markers, goes to fixation through selection at the colony level. An important result of this analysis is that significant differences in the expected equilibrium frequencies between mitochondrial and nuclear markers occur under two conditions: high values of $s$, the selective coefficient of the adaptative locus, and a high initial proportion of European bees. High values for the contribution of the queen to the adaptative value of the colony $(\alpha)$ also favour higher frequencies of nuclear markers of European origin (in relation to mitochondrial markers of the same origin), but only if the above conditions are met.

Extensive sampling of DNAmit polymorphisms in Africanized populations have been carried out in southern Brazilian populations by Moritz \& Meusel
(1992) and Sheppard et al. (1991a). There were different results between these studies in terms of the levels of DNAmit polymorphism and the frequency of European-derived DNAmit haplotypes. It seems that regional differences in the fitness advantage of Africanized bees and population densities of European honeybees have produced variability in the equilibrium frequencies of European genetic markers. Explanations based on general phenomena, such as nuclear-mitochondrial incompatibility or low adaptative value of the hybrids (Harrison \& Hall, 1993), do not explain geographical variability as seems to be supported by the results from Costa Rica and Brazil.

\section{Acknowledgements}

I am grateful to William Ramírez for his assistance with bee collection in the field and his guidance in the main aspects of this research. I also thank Gabriel Aguilar and Rafael Aguilar for technical assistance in the field and in the laboratory. This work was supported by the International Foundation of Science (IFS), grant no. B-1975, and funds from Vicerrectoria de Investigación, Universidad de Costa Rica, grant no. 111-92-207.

\section{References}

DU PRAW, E. J. 1965. The recognition and handling of honeybee specimens in non-Linnean taxonomy. J. Apic. Res., 4, 71-84.

DEL LAMA, M. A., FIGUEREIDo, R. A., SOARES, A. E. E. AND DEL LAMA, S. N. 1988. Hexokinase polymorphism in Apis mellifera and its use for Africanized honeybee identification. Rev. Bras. Genet., 11, 287-297.

DEL LAMA, M. A., LOBO, J. A., SOARES, A. E. E. AND DEL LAMA, S. N. 1990. Genetic differentiation estimated by isozymic analysis of Africanized honeybee populations from Brazil and from Central America. Apidologie, 21, 271-280.

Elandt-Johnson, R. 1971. Probability Models and Statistical Methods in Genetics. John Wiley, New York.

HALL, H. G. 1990. Parental analysis of introgressive hybridization between African and European honeybees using nuclear DNA RFLPs. Genetics, 125, 611-621.

HALL, H. G. AND SMITH, D. R. 1991. Distinguishing African and European honeybee matrilines using amplified mitochondrial DNA. Proc. Natl. Acad. Sci. U.S.A., 88, 4548-4552.

HARRISON, J. F. AND HALL, H. G. 1993. African-European honeybee hybrids have low nonintermediate metabolic capacities. Nature, 363, 258-260.

holdRIDGe, L. R. 1967. Life Zone Ecology. Tropical Science Center, San José, Costa Rica.

LOBo, J. A., Del lamA, M. A. AND meStriner, M. A. 1989. Population differentiation and racial admixture in the African- 
ized honeybee. (Apis mellifera L.). Evolution, 43, 794-802.

LOBO, J. A. AND KERR, w. E. 1993. Estimation of the number of matings in Apis mellifera: extensions of the model and comparison of different estimates. Ethol. Ecol. Evol., 5, 337-345.

LOBO, J. A. AND KRIEGER, H. 1992. Maximum likelihood estimates of gene frequencies and racial admixture in Apis mellifera L. (Africanized honeybees). Heredity, 68 , 441-448.

MARTINS, E., MESTRINER, M. A. AND CONTEL, E. P. B. 1977. Alcohol dehydrogenase polymorphism in Apis mellifera. Biochem. Genet., 15, 357-365.

MiChener, C. D. 1975. The Brazilian bee problem. Ann. Rev. Ent., 20, 399-416.

MORITZ, R. F. A. AND MEUSEL, M. S. 1992. Mitochondrial gene frequencies in Africanized honeybees (Apis mellifera L.): theoretical model and empirical evidence. J. Evol. Biol., 5, $71-81$.

POKLUKAR, J., KEZIC, N. AND POKLUKAR, J. 1994. Estimation of heritability of some characteristics of hind legs and wings of honeybee workers (Apis mellifera carnica Polm) using the half-sibs method. Apidologie, 25, 3-11.

RAMIREZ, w. 1992. Ten years of Africanization in Costa Rica, the experience of a beekeeper. Am. Bee J., 132, 795.

RINDERER, T. E., STELZER, J. A., OLDROYD, B. P., BUCO, S. M. AND RUBINK, W. L. 1991. Hybridization between European and Africanized honey bees in the Neotropical Yucatan Peninsula. Science, 253, 309-311.

SHEPPARD, W. S., SOARES, A. E. E., DEJONG, D. AND SHIMANUKI, H. 1991a. Hybrid status of honey bee populations near the historic origin of Africanization in Brazil. Apidologie, 22, 643-652.

SHEPPARD, W. S., RINDERER, T. E., MAZZOLI, J. A., STELZER, J. A. AND SHIMANUKI, H. 1991b. Gene flow between African- and European-derived honey bee populations in Argentina. Nature, 349, 782-784.

SMITH, D. R., BROWN, W. M. AND TAYLOR, O. R. 1989. Neotropical Africanized honeybees have African mitochondrial DNA. Nature, 321, 674-679.

SPIVAK, M. 1991. The Africanization process in Costa Rica. In: Spivak, M., Fletcher, D. J. C. and Breed, M. D. (eds) The "African" Honey Bee, pp. 137-155. Westview Press, Boulder, CO.

SPIVAK, M. 1992. The relative success of Africanized and European honey-bees over a range of life-zones in Costa Rica. J. Appl. Ecol., 29, 150-162.

SPIVAK, M., RANKER, T., TAYLOR, O., TAYLOR, W. AND DAVIS, L. 1988. Discrimination of Africanized honey bees using behaviour, cell size, morphometrics, and a newly discovered isozyme polymorphism. In: Needham, R. E., Page, R. E. and Delfinado-Baker, M. (eds) Africanized Honey Bees and Bee Mites, pp. 313-324. Ellis Horwood, Chichester.

WINSTON, M. L. 1992. The biology and management of Africanized honey bees. Ann. Rev. Ent., 32, 173-179.

WALLACE, B. 1992. Bottlenecks, soft selection, and Phase III of Wright's 'Shifting Balance' theory. Genetica, 87, 119-125.

\section{Appendix}

\section{Description of the model}

The evolution of the frequencies of racial markers at isozymic and mitochondrial levels in neotropical honeybee populations was simulated with the help of a model of colony-level selection. A hybrid population of drones and virgin queens starts with specific proportions of African or Africanized $(A)$ and European $(1-A)$ bees. Let $N$ be a nuclear or mitochondrial marker fixed in African populations and $n$ be the marker for European bees.

The fitnesses of colonies are determined by a locus with two alleles $(E$ and $e$ ). $E$ alleles are fixed in African bees, which have the highest fitness (highest swarming rate and survival of the colonies). European bees are fixed for the $e$ allele. Racial markers are not linked to the adaptive locus, but they are in complete linkage disequilibrium with it in the first generation.

Fitness values are $1,\left(1-\frac{1}{2} s\right)$ and $(1-s)$ for the $E E$, $E e$ and $e e$ genotypes, respectively, where $s$ is the selection coefficient against European bees. The numbers of drones and queens produced by each colony are weighted by the fitness of the queens and the mean fitness of the workers.

Let $\alpha$ be the proportion of the colony fitness determined by the queen and $p_{\mathrm{e}}$ be the frequency of the $e$ allele in the drone population. Also, let $W_{\mathrm{EE}}, W_{\mathrm{Ee}}$ and $W_{\text {ee }}$ be the fitnesses of colonies headed by $E E, E e$ and $e e$ queens, respectively. After calculating the mean fitness of workers, the $W$ values for each of the three

Table 5 Equilibrium frequencies of nuclear (bold) and mitochondrial European neutral alleles in populations resulting from the mixing of African and European races, with selection fixing African adaptive genes

\begin{tabular}{|c|c|c|c|c|c|c|}
\hline \multirow[b]{2}{*}{$s$} & \multicolumn{2}{|c|}{$A=0.25$} & \multicolumn{2}{|c|}{$A=0.5$} & \multicolumn{2}{|c|}{$A=0.75$} \\
\hline & $\alpha=0$ & $\alpha=1$ & $=0$ & $\alpha=1$ & $\ell=0$ & $\alpha=1$ \\
\hline \multirow[t]{2}{*}{0.95} & ก 273 & 0 & 0.228 & 0.1 & 0.109 & \\
\hline & & & 162 & & 81 & \\
\hline \multirow[t]{2}{*}{0.75} & 0.499 & 0.3 & 0.293 & & 35 & 0.066 \\
\hline & 0.42 & 0.1 & 0.244 & 0.0 & 0.112 & 0.034 \\
\hline \multirow[t]{2}{*}{0.50} & 0.620 & & 71 & & 172 & 0.113 \\
\hline & 0 . & & 3 & & & 0.087 \\
\hline \multirow[t]{2}{*}{0.25} & 0.700 & 0.6 & 0.442 & 0. & 0 . & o. \\
\hline & 0.689 & 0.62 & 0.429 & 0.3 & 0.202 & 0.161 \\
\hline \multirow[t]{2}{*}{0.05} & 0.741 & 0.73 & 0.489 & 0.4 & 0.242 & 0.234 \\
\hline & 0.740 & 0.730 & 0.487 & 0.474 & 0.240 & 0.231 \\
\hline
\end{tabular}

See text for explanations of symbols. 
kinds of colonies will be:

$$
\begin{aligned}
& W_{\mathrm{EE}}=\alpha+(1-\alpha)\left(1-\frac{1}{2} p_{\mathrm{e}} s\right), \\
& W_{\mathrm{Ee}}=\alpha\left(1-\frac{1}{2} s\right)+(1-\alpha)\left(1-\frac{1}{4} s\left(1+2 p_{\mathrm{e}}\right)\right) \text { and } \\
& W_{\mathrm{ee}}=\alpha(1-s)+(1-\alpha)\left(1-\frac{1}{2} s-\frac{1}{2} s p_{\mathrm{e}}\right) .
\end{aligned}
$$

Equilibrium gene frequencies for the racial markers can be obtained by iterating several generations of selection and random mating. Values for the next generation can be obtained from the following transition matrix for the nuclear marker, where $z_{1}, z_{2}, z_{3}$ and

\begin{tabular}{|c|c|c|c|c|c|c|c|c|c|c|c|c|c|}
\hline \multirow[b]{2}{*}{ Queen } & \multicolumn{9}{|c|}{ Female progeny } & \multicolumn{4}{|c|}{ Male progeny } \\
\hline & $E E N N$ & EeNN & $e e N N$ & $E E N n$ & EeNn & $e e N n$ & EEnn & Eenn & eenn & $E N$ & $e N$ & En & en \\
\hline EENN & $z_{1}$ & $z_{2}$ & 0 & $y_{1}$ & $y_{2}$ & 0 & 0 & 0 & 0 & 1 & 0 & 0 & 0 \\
\hline EeNN & $\frac{1}{2} z_{1}$ & $\frac{1}{2}\left(z_{1}+z_{2}\right)$ & $\frac{1}{2} z_{2}$ & $\frac{1}{2} y_{1}$ & $\frac{1}{2}\left(y_{1}+y_{2}\right)$ & $\frac{1}{2} y_{2}$ & 0 & 0 & 0 & $\frac{1}{2}$ & $\frac{1}{2}$ & 0 & 0 \\
\hline$e e N N$ & 0 & $z_{1}$ & $z_{2}$ & 0 & $y_{1}$ & $y_{2}$ & 0 & 0 & 0 & 0 & 1 & 0 & 0 \\
\hline EENn & $\frac{1}{2} z_{1}$ & $\frac{1}{2} z_{2}$ & 0 & $\frac{1}{2}\left(z_{1}+z_{3}\right)$ & $\frac{1}{2}\left(z_{4}+z_{2}\right)$ & 0 & $\frac{1}{2} z_{3}$ & $\frac{1}{2} z_{4}$ & 0 & $\frac{1}{2}$ & 0 & $\frac{1}{2}$ & 0 \\
\hline EeNn & $\frac{1}{4} z_{1}$ & $\frac{1}{4}\left(z_{1}+z_{2}\right)$ & $\frac{1}{4} z_{2}$ & $\frac{1}{4}\left(z_{1}+z_{3}\right)$ & $\frac{1}{4}$ & $\frac{1}{4}\left(z_{2}+z_{4}\right)$ & $\frac{1}{4} z_{3}$ & $\frac{1}{4}\left(z_{3}+z_{4}\right)$ & $\frac{1}{4} z_{4}$ & $\frac{1}{4}$ & $\frac{1}{4}$ & $\frac{1}{4}$ & $\frac{1}{4}$ \\
\hline$e e N n$ & 0 & $\frac{1}{2} z_{1}$ & $\frac{1}{2} z_{2}$ & 0 & $\frac{1}{2}\left(z_{1}+z_{3}\right)$ & $\frac{1}{2}\left(z_{2}+z_{4}\right)$ & 0 & $\frac{1}{2} z_{3}$ & $\frac{1}{2} z_{4}$ & 0 & $\frac{1}{2}$ & 0 & $\frac{1}{2}$ \\
\hline EEnn & 0 & 0 & 0 & $z_{1}$ & $z_{2}$ & 0 & $z_{3}$ & $z_{4}$ & 0 & 0 & 0 & 1 & 0 \\
\hline Eenn & 0 & 0 & 0 & $\frac{1}{2} z_{1}$ & $\frac{1}{2}\left(z_{1}+z_{2}\right)$ & $\frac{1}{2} z_{2}$ & $\frac{1}{2} z_{3}$ & $\frac{1}{2}\left(z_{3}+z_{4}\right)$ & $\frac{1}{2} z_{4}$ & 0 & 0 & $\frac{1}{2}$ & $\frac{1}{2}$ \\
\hline eenn & 0 & 0 & 0 & 0 & $z_{1}$ & $z_{2}$ & 0 & $z_{3}$ & $z_{4}$ & 0 & 0 & 0 & $1 y$ \\
\hline
\end{tabular}
$z_{4}$ are the male frequencies of $E N, E n, e N$ and $e n$ gametes.

\begin{tabular}{|c|c|c|c|c|c|c|c|c|c|c|}
\hline \multirow[b]{2}{*}{ Queen } & \multicolumn{6}{|c|}{ Female progeny } & \multicolumn{4}{|c|}{ Male progeny } \\
\hline & $E E N$ & $E e N$ & $e e N$ & $E E n$ & Een & een & $E N$ & $E n$ & $e N$ & en \\
\hline EEN & $z_{1}+z_{3}$ & $z_{2}+z_{4}$ & 0 & 0 & 0 & 0 & 1 & 0 & 0 & 0 \\
\hline$E e N$ & $\frac{1}{2}\left(z_{1}+z_{3}\right)$ & $\frac{1}{2}$ & $\frac{1}{2}\left(z_{2}+z_{4}\right)$ & 0 & 0 & 0 & $\frac{1}{2}$ & 0 & $\frac{1}{2}$ & 0 \\
\hline$e e N$ & 0 & $z_{1}+z_{3}$ & $z_{2}+z_{4}$ & 0 & 0 & 0 & 0 & 0 & 1 & 0 \\
\hline$E E n$ & 0 & 0 & 0 & $z_{1}+z_{3}$ & $z_{2}+z_{4}$ & 0 & 0 & 1 & 0 & 0 \\
\hline Een & 0 & 0 & 0 & $\frac{1}{2}\left(z_{1}+z_{3}\right)$ & $\frac{1}{2}$ & $\frac{1}{2}\left(z_{2}+z_{4}\right)$ & 0 & $\frac{1}{2}$ & 0 & $\frac{1}{2}$ \\
\hline een & 0 & 0 & 0 & 0 & $z_{1}+z_{3}$ & $z_{2}+z_{4}$ & 0 & 0 & 0 & $1 y$ \\
\hline
\end{tabular}

The following would be the matrix for the mitochondrial marker.

Genotypic frequencies for the next generation are given by the sum of the elements of the respective column after weighting by the respective colony fitness and the frequency of the queen genotype. In the first generation there will be only two diploid genotypes (EENN and eenn, or EEN and een) and two haploid ones $(E N$ and $e n)$, with frequencies determined by the racial admixture proportions.

Equilibrium frequencies of nuclear and mitochondrial racial markers will be reached in a few generations, when the gametic disequilibrium generated by the admixture vanishes by recombination.

Table 5 shows equilibrium frequencies for a range of values of $s, A$ and $\alpha$. It can be seen that high values of $s$ and high initial proportions of European bees, with colony fitness strongly determined by the queen genotype, will generate maximum differences between the final frequencies of nuclear and mitochondrial markers.

The above model has some important differences from the one used by Moritz \& Meusel (1992). Individual fitnesses of queen and drones are not considered here because it is assumed that most of the fitnesses differences in this context depend on survival and reproduction of colonies. Furthermore, instead of a single mating, it is assumed that the gamete frequencies of the drones mated with a queen are equal to the population male frequencies because of the high number of matings in Africanized populations (mean of 16; Lobo \& Kerr, 1993). 